\title{
BIBLIOTECA DE ORIENTAÇÃO DA PROFESSORA PRIMÁRIA E O VOLUME HABILIDADES DE ESTUDOS SOCIAIS NO PROGRAMA BRASILEIRO-AMERICANO DE ENSINO ELEMENTAR (PABAEE) 1956-1964
}

\author{
Susane da Costa Waschinewski ${ }^{1}$ \\ Giani Rabelo ${ }^{2}$
}

\section{INTRODUÇÃO}

Nos finais do século $\mathrm{XIX}$ e ao longo do século $\mathrm{XX}$, o processo de institucionalização da escola no Brasil intensificou a produção de uma cultura material escolar (GASPAR DA SILVA; PETRY, 2011), por meio de materiais pedagógicos como cadernos, manuais, mobiliários. Para tanto, o estudo desses materiais escolares nos ajudam a compreender a cultura escolar e todo o contexto da educação em diferentes períodos. Nesse sentido, essa pesquisa em andamento busca analisar no manual escolar Biblioteca de Orientação da Professôra Primária, volume "Habilidades de Estudos Sociais", os preceitos de civilidade que se pretendia ensinar por meio do conteúdo desta disciplina.

A Biblioteca de Orientação da Professôra Primária écomposta por um conjunto de manuais que é parte integrante dos materiais didáticos produzidos para o aperfeiçoamento de professores/as no Programa BrasileiroAmericano de Ensino Elementar (PABAEE). O programa ocorreu entre os anos de 1956-1964, no período conhecido como desenvolvimentista, durante o governo de Juscelino Kubitschek (1956 a 1961). O acordo entre Brasil e Estados Unidos (EUA), tendo como objetivo reduzir os índices de evasão e repetência das escolas primárias brasileiras. Por essa razão, previam-se como principais ações a formação de professores/as e a produção de materiais didáticos.

Assim, propor o estudo do manual escolar não é uma tarefa fácil, pois ao passo que temos uma fonte privilegiada "temos uma dupla dimensão (objeto e fonte)" (GALVÃO; BATISTA, 2003), o que nos deixa a mercê de

\footnotetext{
${ }^{1}$ Mestranda no Programa de Pós Graduação em Educação- UNESC suzanegeo@hotmail.com

${ }^{2}$ Professora do Programa de Pós-Graduação em Educação da UNESC - grã@unesc.net
} 
assumir o discurso da fonte ou realizar uma análise muito descritiva. Contudo, busca-se um investimento na análise do corpus documental gerando aproximações dos modos de ensinar e de instruir, uma vez que o discurso presente no exemplar que circulou no período tinha como objetivo construir uma nova sociedade. Por esse motivo,pretende-se analisá-los tanto em seus suportes materiais como em seus dispositivos textuais, com o fito de mapear o conjunto das regras e orientações que compõem o repertório de civilidades em tal época. A partir da análise deste material poderei identificar as regras e os preceitos voltados à regular comportamento (hábitos de asseio pessoal, prescrições de leitura, maneiras de portar-se), com vistas à construção de práticas de convívio sociabilidade que procurariam evidenciar uma pessoa bem educada.

O interesse em pesquisar essa temática ocorreu devido a minha participação no projeto de pesquisa (em andamento) intitulado Desenvolvimento, Educação e Planejamento em Santa Catarina (1955-2010³), que tem como objetivo analisar a trajetória e a relação entre os planos nacionais e estaduais de educação com os planos nacionais e estaduais de desenvolvimento, bem como suas orientações para a formulação das políticas públicas educacionais em Santa Catarina.

Nos primeiros passos dados no desenvolvimento deste projeto de pesquisa foram surgindo inúmeras curiosidades, entre elas, o interesse em saber como as políticas desenvolvimentistas e de modernização incidiram sobre o processo educacional brasileiro. Nos primeiros levantamentos das fontes, chamou minha atenção às mensagens presidenciais, em especial, o discurso de cunho nacional desenvolvimentista, no tocante à necessidade de formar mão de obra qualificada, da expansão do ensino, dos investimentos na educação e na formação de professores/as, bem como os acordos políticos e financeiros com o capital estrangeiro, principalmente com o governo norteamericano.

Doravante, em consultas a base de alguns dados encontrei estudos como os das pesquisadoras Edil Vasconcellos Paiva e Léa Pinheiro Paixão

\footnotetext{
${ }^{3}$ Projeto aprovado no edital MCTI/CNPQ Universal 14/2014, pela professora Dra. Giani Rabelo (ano inicio e final).
} 
denominado PABAEE (1956-1964): a americanização do ensino elementar ${ }^{4}$, no qual as autorasrealizam uma pesquisa sistemática estudando o surgimento e a trajetória do programa de assistência técnica norte-americana junto ao ensino elementar brasileiro.

Destaca-se ainda a pesquisa da professora Neide de Almeida Fiori, O Programa Brasileiro-Americano de Assistência ao Ensino Elementar (PABAEE) segundo memórias de uma aluna/professora. Todavia,nota-secerta ausência nas pesquisas referentes ao programa, a coleção de Orientação a professôra primária e a participação das professoras catarinenses no programa de assistência.

\section{METODOLOGIA}

O caminho percorrido para alcançar os objetivos dessa pesquisa se constitui-se no campo da pesquisa qualitativa, e na análise documental que de acordo com Minayo (2001, p.22), a pesquisa qualitativa "[..] trabalha com 0 universo de significados, motivos, aspirações, crenças, valores e atitudes" o que retribui a um espaço mais profundo das relações, os quais não podem ser reduzidos à operacionalização de variáveis.

Segundo Lüdke e André (1986, p. 38), "a análise documental pode se constituir numa técnica valiosa de abordagem de dados qualitativos seja complementando as informações obtidas por outras técnicas, seja desvelando aspectos novos de um tema ou problema".

Ao trabalhar com um conjunto de documentos busco vestígios que me permitam montar um emaranhado de relações que combinadas forneçam aproximações do real. Fazendo-se necessário ao longo da trajetória da pesquisa buscar referenciais teóricos, que com suas reflexões pudessem me afastar de algumas armadilhas e ciladas que facilmente podem ocorrer. Nesse sentido destaco a importância do cruzamento das fontes, conforme versou as autoras Lopes e Galvão (2001, p. 92 - 93), que abordam esse procedimento metodológico e fazem a seguinte observação:

${ }^{4}$ PABAEE (1956-1964) A americanização do ensino elementar no Brasil?/ EdilVasconcelos de Paiva. Léa Pinheiro Paixão. - Niterói: EUFF, 2002. 
O cruzamento e confronto das fontes poderá também ajudar no controle da subjetividade do pesquisador. É uma operação indispensável. Há uma expressão antiga que diz bastante do incansável trabalho que se há de ter com o entretecer do problema, com as questões formuladas e a ida às fontes: "da bigorna forja, da forja à bigorna".

Já o historiador Le Goff nos ajuda a compreender de formal conceitual o documento sem perder de vista que esses documentos carregam consigo intencionalidades, que não são neutros, ou seja, foram construídas em um campo de relações de poder:

O documento não é inocente, não decorre apenas da escolha do historiador, ele próprio parcialmente determinado por sua época e seu meio; o documento é produzido consciente ou inconscientemente pelas sociedades do passado, tanto para impor uma imagem desse passado, quanto para dizer "a verdade". (LE GOFF, 2004, p. 54).

Encontrar os documentos referentes à participação das professoras no programa de assistência foi um dos primeiros obstáculos na pesquisa, sem dúvida um dos momentos mais angustiantes, pois ao encontrar os documentos espera-se esclarecer dúvidas que cercam e limitam o objeto de investigação. Ao realizar a pesquisa de campo nos arquivos na obra de ArletteFarge, $O$ Sabor do Arquivo contribuiu para compreender muitos aspectos da imersão nos locais de pesquisa e o contato com os documentos impressos. Para a autora Farge (2009, p.11),

$O$ arquivo não se parece nem com texto, nem com os documentos impressos, nem com os "relatos", nem com as correspondências, nem com os diários, e nem mesmo com as autobiografias. É difícil sem sua materialidade. Por quanto desmesurado, invasivo como as marés de equinócios, as avalanches ou as inundações.

O arquivo carrega milhões de histórias, personagens, fatos ocorridos, prontos para serem revisitados, problematizados tornando-se fontes ricas de pesquisa. A autora permite a similitude com os fluxos da natureza com o fundo dos oceanos, que se comparam com os fundos dos porões com numerosas sessões de documentos. Por inúmeras estantes, sessões 
intermináveis de documentos, eis que nos deparamos com a ausência, o silêncio que ronda a busca por documentos que cerquem o objeto pesquisado.

Dessa forma as etapas da pesquisa se desenvolvem na seguinte forma: a) Levantamento dos locais de pesquisa: nessa primeira etapa procurou-se realizar um levantamento nas bases online, inventários e anuários sobre os temas pesquisados, mapeando os possíveis locais de pesquisa.

Estabelecido os locais de pesquisa e os documentos que se pretendia encontrar, foi realizado um contato prévio, realizando o agendamento das visitas e procurando informações sobre as condições dos documentos e como eles poderiam ser acessados (foto, cópias, compilação); b) Visita aos arquivos: os arquivos visitados foram o Instituto de Documentos e Investigação em Ciências Humanas (IDHC), Arquivo Público de Santa Catarina, Biblioteca Pública de Santa Catarina - Setor Obras Raras, Secretaria da Educação de SC Diretoria de Gestão de Pessoas (DIGP). Arquivo da Faculdade de Educação (FAED) na Universidade do Estado de Santa Catarina (UDESC), Biblioteca UDESC e Biblioteca UNESC; c) Coleta dos dados: durante as pesquisas nos arquivos foi possível entrar em contato com uma imensidão de documentos impressos.

O processo de coleta consistiu na realização de algumas escolhas, sendo necessário selecionar de acordo com o problema da pesquisa os artigos, jornais, revistas, decretos, periódicos, entre outros os que mais se aproximavam do objeto de pesquisa e que assim poderiam contribuir para montar as investigações. As coletas foram realizadas por meio de fotografias e compilação de alguns documentos; d) Catalogação dos dados: após a coleta dos dados foi possível realizar a organização dos arquivos, sendo que as mensagens presidências foram digitadas em tabelas organizadas por temas e assuntos e datas. Os jornais coletados na biblioteca pública foram organizados em temas e direcionados as pastas dos capítulos que serão analisados, assim como os demais documentos que foram todos previamente identificados, catalogados e inseridos nas pastas dos capítulos. Em relação ao manual Biblioteca de Orientação da professora primária, Habilidades de Estudos sociais, após a leitura foi construído uma tabela para identificar a frequência dos preceitos de civilidade contidos nos dispositivos textuais. 


\section{O PROGRAMA BRASILEIRO-AMERICANO DE ENSINO ELEMENTAR (PABAEE) NO CONTEXTO DESENVOLVIMENTISTA}

Em relação ao cenário nacional após a eleição de Juscelino Kubitscheck, em 1956, o então presidente lança seu plano de governo chamado de Plano de Metas.O Plano de Metas almejava vastos investimentos nos setores de energia, transportes, alimentação, indústrias de base e incentivo à indústria automobilística.

Para o sociólogo Octaviolanni (1996, p. 160), o Programa de Metas visava transformar a estrutura econômica do país alicerçada em investimentos para a criação de indústrias de base e a reformulação das condições reais de interdependência com o capitalismo mundial. $O$ desdobramento desse novo processo implicou na emergência de novas situações, gerando assim a necessidade de mão de obra qualificada, ou seja, homens e mulheres alfabetizados/as e instruídos/as que pudessem trabalhar na indústria. Diante desse novo contexto foi necessário pensar na formação da mão de obra trabalhadora, bem como nas políticas que pudessem solucionar tais carências de maneira rápida. A necessidade de resolver essa lacuna pautou a educação como carro chefe no processo de desenvolvimento e modernização da sociedade brasileira, ganha destaque no discurso do binômio Educação para $o$ Desenvolvimento.Assim, alguns investimentos ocorreram no campo educacional, inclusive no pacote direcionado à considerada assistência à América Latina.

Segundo as autoras Paiva e Paixão (2002, p.61), a partir do "Acordo sobre Serviços Técnicos Especiais, o governo americano concordou em colocar à disposição do governo brasileiro serviços técnicos". Um dos focos desta assistência era o ensino secundário (organizado em dois ciclos: o primeiro de quatro anos, conhecido como Ginásio e o segundo ciclo de três, chamado de Colégio) ligado diretamente à formação industrial e desse modoo acordo foi denominado de Programa de Assistência Brasileiro-Americana à Educação de Ensino Secundário (PABAEES).

Não obstante era visível que os desafios educacionais eram enormes e que a assistência apenas ao ensino secundário não garantiria os 
resultados esperados, pois as defasagens partiam de processos educacionais anteriores, os quais deveriam ser repensados, como a própria formação de professores/as. Logo o programa volta-se para a experiência do Ensino Elementar brasileiro.

Em 1956, tendo como secretário da Educação e Cultura Clóvis Salgado ${ }^{5}$, foi assinado o acordo para a execução do Programa de Assistência Brasileiro-Americana à Educação de Ensino Elementar (PABAEE), que tinha como prioridades: a) formar professores do ensino normal, b) elaborar materiais didáticos, c) enviar aos Estados Unidos professores de ensino normal e elementar para realizar curso de aperfeiçoamento (PAIVA; PAIXÃO, 2002).

Para cumprir tais objetivos estava previsto que o programa seria desenvolvido até o ano de 1961, porém acordos posteriores (como a difusão do PABAEE em todo território nacional) levaram a duração dessa assistência até $1^{\circ}$ de agosto de 1964. A execução do programa ficou sob a responsabilidade do Instituto Nacional de Estudos Pedagógicos (INEP), que na época era dirigido por Anísio Teixeira.

O período em que se desenvolve o PABAEE é marcado pelo movimento econômico em que o país vivenciava, sendoque o convênio será considerado um ponto importante nas estratégias de desenvolvimento tal como na trajetória do planejamento econômico do país, pois para muitos estudiosos esse plano é considerado a primeira experiência em planejamento estatal posto em prática.

De acordo com o economista Guido Mantega (1984 p. 72), O Plano de Metas constitui o coroamento da "política" de desenvolvimento traçada pela Comissão Mista Brasil - Estados Unidos. Essa comissão criada pelo Ministério da Fazenda, formada por técnicos brasileiros e norte-americanos, tinha por tarefa a elaboração de políticas para o desenvolvimento econômico do país, além de inúmeras outras áreas estratégicas como projetos técnicos de energia e de transportes.

Segundo Benevides, nesse momento ocorre uma "congregação da iniciativa privada crescida substancialmente de capital e tecnologia estrangeira com a intervenção contínua do Estado, como orientador dos investimentos

\footnotetext{
${ }^{5}$ Clóvis Salgado foi Ministro da Educação e Cultura 31-01-56 a 31-01-61.
} 
através de planejamento" (BENEVIDES, 1979, p.202). Intensificava-se assim a abertura de capital estrangeiro e ampliando o avanço no desenvolvimento do país.

A marca de Juscelino para concretizar essa política de modernização foi desenvolvida sob o slogan "cinqüenta anos em cinco". Política a qual previa o crescimento e desenvolvimento econômico do país em cinco anos, o que levaria em um transcorrer de tempo de cinquenta anos. Essas metas só poderiam ser materializadas por meio da ação governamental pautadas no Plano de Metas, nessa concepção compreendia-se o estado como planejador, com o poder de pensar, intervir e regular realizando diversas políticas setoriais, inclusive educacionais.

\section{REFERÊNCIAS}

BARDIN L. Análise de conteúdo. Lisboa: Edições 70; 1977

BENEVIDES, Maria Victoria de Mesquita. 0 governo Kubitschek: desenvolvimento econômico e estabilidade política (1956-1961). Rio de Janeiro: Paz e Terra, 1979.

FARGE, Arlette. O sabor do arquivo. São Paulo: Edusp, 2009.

GALVÃO, A.M.; BATISTA, A.A.G. Manuais escolares e pesquisa em História. In: C.G. VEIGA; T.N.L. FONSECA, História e Historiografia no Brasil. Belo Horizonte, Autêntica, 2003, p. 161-18.

GASPAR DA SILVA, V. L.; PETRY, M. G. (Org.). Objetos da escola: espaços e lugares de constituição de uma cultura material escolar (Santa Catarina - séculos XIX e XX). Florianópolis: Insular, 2011.

IANNI, Octavio. Estado e Planejamento no Brasil. Rio de Janeiro: Civilização Brasileira,1996.

LE GOFF,Jacques. A História Nova/[sob a direção] Jacques Le Goff, Roger

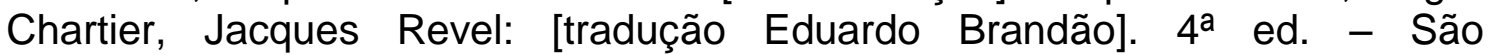
Paulo:Martins Fontes, 198.

LOPES, Eliane Marta Teixeira; GALVÃO, Ana Maria de Oliveira. História da educação: o que você precisa saber sobre. Rio de Janeiro: DPA, 2001.

LÜDKE, Menga; ANDRÉ, Marli E.D.A. Pesquisa em Educação: abordagens qualitativas. São Paulo: EPU, 1986. 
MANTEGA, Guido. A economia política brasileira. Rio de Janeiro, Polis/Vozes, 1984.

MINAYO, Maria. C. S. Ciência, técnica e arte: o desafio da pesquisa social. In: ; Maria. C. S (Org.). Pesquisa social: teoria, método e criatividade. Petrópolis, RJ: Vozes, 2001.

PESAVENTO, Sandra Jatahy. História e história cultural. Belo Horizonte: Autêntica, 2003.

SAVIANI, D. A nova lei da educação: trajetória, limites e perspectivas. Campinas: Autores Associados, 1997. 